\title{
Capacity of Internet Usage by On-Campus Undergraduate Elementary School Teachers in Kenyan University Setting
}

\author{
Philip K. Mwei, Jackson K. Too
}

\author{
Department of Curriculum, Instruction and Educational Media, Moi University
}

\begin{abstract}
In the contemporary society, internet is becoming part and parcel of our lives and hence in the lives of teachers and their students alike is not an exception. This study investigated the capacity of internet usage by on-campus pre-service teachers in an undergraduate degree program in elementary school option. "Internet scale" was developed and validated using a pilot sample and yielded a reliability coefficient of Cronbach alpha of 0.77. Proportionate random sampling from each of the four years (cohorts) of study resulted to a sample size of 79 respondents. Both descriptive and inferential data analyses were conducted on the collected data. The findings of this study revealed that internet usage by pre-service teachers was very low. A major recommendation is that as computer ownership is increasingly advocated, equipping college libraries with enough Internet-connected computers and WIFI services should be taken into account.
\end{abstract}

Keywords: Internet, Internet Usage, Pre-service teachers, ICT, Elementary school

\section{INTRODUCTION}

Information and communication technologies (ICTs) are becoming the most important element that defines students' basic competencies at all education levels globally (Aladejana, 2007). Education systems the world over are adopting the use of ICT, notably e-learning and other learning management systems (LMSs) particularly in university education as a result of the increasing availability of internet-based applications (Yidirim, Korusu, Aktas \& Kule, 2010). In the developing world such as majority of the countries in Africa, diffusion of ICT into education, specifically the Internet is slow. In Kenya, for instance, KENET is tasked with the responsibility to oversee internet connectivity in tertiary institutions (universities and polytechnics).

As universities adopt e-learning systems to enhance Open and Distance Education (ODE), residential students alike will tremendously benefit from this innovation. With e-learning systems, teachers and students can share course announcements such as, course outlines or syllabus course notes, documents, and assignment submission (Yildrim et al. 2010). Bahk (2008) posits that the internet has reshaped traditional forms and practices of human interaction and information management. This observation has the implication that in the $21^{\text {st }}$ century, both teachers and students should possess competencies that enable them to work with these emerging technologies. Therefore, it is imperative that the capacity of internet use by pre-service teachers who will be handling students with diverse ICT backgrounds be investigated. The assumption is that pre-service teachers' competences will have a direct impact on their students ICT competencies in the future.

Presently, primary and secondary schools are integrating ICT into their instructional processes, thus teacher education should produce teachers with ICT competencies. Pre-service teachers are expected to be users of technology within and without their classroom settings, implying that pre-service teachers should be proficient or Internet-literate in use of technology (Onwuagboke, Singh, \& Fook, 2014; Firat \& Serpil, 2017). Technology should be an essential part of teacher education. Society for Information Technology and Teacher Education, SITE (2002) identified basic principles for the development of an effective ICT teachers' education program as: (a) Technology should be infused into the entire teacher education program. Students should learn about and with technology and how to incorporate into their own teaching. (b) Technology should be introduced in context beyond computer literacy; that is, the professional literacy - learning to use technology to foster the education growth of students. (c) Students should experience innovative technology learning environment to support traditional forms of learning as well as to transform learning. These principles (SITE 2002) 
advocate for an innovative ICT, rich teaching-learning environment that becomes a way of life for both students and teachers. If ICT is infused into professional literacy (pedagogical knowledge) of pre-service teachers, the concept of "digital native - migrant" divide is bridged and effective use of ICT is achieved.

UNESCO (2002) identified four ICT competencies that go well with the SITE principles. These competencies should be acquired by teachers in order to be successful in their practice and the entire professional life. First, the pedagogy focused on teachers' instructional practices and knowledge of the curriculum. This principle requires that teachers develop applications or instructional programs within their disciplines that make effective use of ICT to support and extent teaching and learning. Secondly, collaboration and networking that acknowledges the communication potential of ICTs. This principle revolves around the belief that ICTs can extend learning beyond the classroom wall and the implications for the teachers' development of new knowledge and skills. Thirdly, social issues that technology brings with it new rights and responsibilities. These social issues encompass access to technology resources, care for individual health, and respect for intellectual property (read copyright and plagiarism). Finally, the technology issues as an aspect of the lifelong learning theme (also Keller, Lindh, Hrastinki, Casanovas \& Fernandez, 2009) through which teachers update skills with hardware and software as new generations of technology emerge.

The need to acquire the ICT competencies is enormous and leaves pre-service teachers with little choice. This study made an assumption that since basic principles for teachers' education and ICT competencies articulate the central role played by ICT, in particular the internet, there is need to understand how pre-service teachers use the internet. According to Smith and Greene (2013), the inclusion of $21^{\text {st }}$ century "technology" skills in teaching serves as one of the "multiple realities of implementing quality preparation and support of teacher educators" (p. 121).

Bahk (2008) identified internet involvement as an index of internet usage and defined it as the extent to which an individual gets involved in the usage of the internet in their daily lives. Not completely following in this tradition this study considered internet usage as the capacity of an elementary preservice teacher to execute some specific tasks (academic or non academic) using the internet and the duration the elementary pre-service teacher is involved with the internet at one go.

\section{MAterials AND MethodS}

This section will address three major issues: research questions, sample and techniques used to obtain it and instrument development and validation.

\section{Research Questions}

The study set out to answer the following questions:

1. What are the sources of pre-service teachers' internet services?

2. Do what extent pre-service teachers use the internet for specific tasks?

3. What demographic factors affect pre-service teachers' internet use?

\section{Sample and Sampling Techniques}

The target population for the study was all pre-service teachers (First through Fourth year of study) pursuing a Bachelors degree in elementary education (Early Childhood and Primary Education, ECPE) in a public university in Kenya. A proportionate sample of $56 \%$ from each year of study was used and yielded 79 respondents.

\section{Instrumentation}

Review of literature (Onwuagboke et al., 2014; Adediran \& Kehinde, 2014; Lei, 2009) and preliminary inquiry from a sample of five students (non ECPE) were employed in the development of the research instrument on internet use. The internet use scale consisted of nine Likert-type items indicating the frequency of internet use for specific tasks, scored: $\mathbf{5}=$ More than once daily; $\mathbf{4}=$ Once daily; $\mathbf{3}$ = several times in a week; $\mathbf{2}=$ several times in a month; $\mathbf{1}=$ several times in a semester; and $\mathbf{0}$ $=$ Never. The internet use scale was as follows:

How often do you perform the following tasks using the Internet?

1. Search for information for my academic tasks (e.g., assignments, projects, essays, etc).

2. Assist my colleagues search for information for their academic tasks. 
3. E-mail friends for non-academic purposes (e.g., socialization, national news, domestic affairs, etc)

4. E-mailing colleagues for academic purposes (e.g., information about lectures, assignments, references, etc)

5. For fun/leisure (e.g., playing online games, facebook, tweeter, etc).

6. Academic blogs for academic subjects discussions

7. Reading daily newspapers

8. Chatting on academic platforms with colleagues and lecturers

9. Learning about the internet: navigation, opening and saving documents/web pages, etc.

\section{RESUlts}

\section{Sample Characteristics}

The samples characteristics considered as independent variables were: Gender, age, year of study and computer ownership. Tables 1 to 4 give a summary of these variables. Table 1 indicates that majority of the respondents are female which is a representation of gender disparity in ECPE programs that are more biased to females. Majority, 54 (68.4\%) of the pre-service teachers are 24 years and below. The First Years were the majority followed by the Fourth years as a result of the proportionate sampling. Majority (74.7\%) pre-service teachers still do not own computers.

Table1. Gender of Respondents

\begin{tabular}{|c|c|c|}
\hline Gender & $N$ & $f(\%)$ \\
\hline Female & 54 & 68.4 \\
\hline Male & 25 & 31.6 \\
\hline
\end{tabular}

Table2. Age of respondents

\begin{tabular}{|c|c|c|}
\hline Age (in Years) & $N$ & $f(\%)$ \\
\hline $19-21$ & 24 & 30.4 \\
\hline $22-24$ & 30 & 38.0 \\
\hline $25-27$ & 14 & 17.7 \\
\hline $28-30$ & 11 & 13.9 \\
\hline
\end{tabular}

Table3. Respondents year of study

\begin{tabular}{|c|c|c|}
\hline Year of study & $N$ & $f(\%)$ \\
\hline First & 26 & 32.9 \\
\hline Second & 14 & 17.7 \\
\hline Third & 19 & 24.1 \\
\hline Fourth & 20 & 25.3 \\
\hline
\end{tabular}

Table4. Computer Ownership by Respondents

\begin{tabular}{|c|c|c|}
\hline Computer Ownership & $N$ & $f(\%)$ \\
\hline YES & 20 & 25.3 \\
\hline NO & 59 & 74.7 \\
\hline
\end{tabular}

\section{Research question 1}

What are the sources of pre-service teachers' internet services?

To answer this question, participants were asked to indicate their internet sources (Table 5). Table 5 indicates that majority $56(70.9 \%)$ of respondents use their phones for internet services while slightly more than $50 \%$, that is, $42(53.2 \%)$ do not use college library. The order of decreasing use of internet sources by pre-service teachers is phone, cyber cafes, library and modem. Forty three (54.4\%) do not use cyber cafes for Internet services compared to $36(45.6 \%)$ who use them. These results are comparable to the findings of Onwuagboke et al. (2014) who found that pre-service teachers in a Nigerian College of Education use mobile phones at $60.4 \%$ and public cybercafés at $26.5 \%$.

Table5. Sources of internet for the respondents

\begin{tabular}{|l|c|c|c|c|}
\hline & \multicolumn{4}{|c|}{ Source of Internet } \\
\hline & Phone & College Library & Cyber cafes & Modem \\
\hline YES & $56(70.9)$ & $37(46.8)$ & $36(45.6)$ & $7(8.9)$ \\
\hline NO & $23(29.1)$ & $42(53.2)$ & $43(54.4)$ & $72(91.1)$ \\
\hline
\end{tabular}


These results are inconsistent with other findings, for example, Mishra (2009) and Omotayo (2006) who found that majority of respondents access Internet through cybercafés. Particularly, Mishra (2009) established that $62.3 \%$ of the respondents gained Internet services via cybercafés.

\section{Research question 2}

Do what extent pre-service teachers use the internet for specific tasks?

The internet use scale consisting of nine-items was used. An internal consistency reliability coefficient (Cronbach $\alpha$ ) of 0.87 was obtained from the main study, with scale properties $(M=17.19$, $S D=9.98$ ). Table 6 shows the frequencies or the number of respondents obtaining a particular score (between 0 and 1), means and standard deviations for each internet use scale items. From Table 6, item means reveal the following:

1. Two items (1and 5) had means close to $3(2.5 \leq \mathrm{M}<3.5)$. This indicates that these tasks are on average performed "several times in a week".

2. Five items $(2,3,6,7$, and 9) had means close to $2(1.5 \leq M<2.5)$. This indicates that these tasks are on average performed "several times in a month."

3. Two items (4 and 8) had means close to $1(0.5 \leq \mathrm{M}<1.5)$. This indicates that these tasks are on average performed "several times in a semester".

4. None of the items had a mean of 0 (Never), 4 (once daily) and 5 (more than once daily).

5. Item 8 had $30(38.0 \%$ ) respondents at 0 (never) followed by item 7 with $25(31.6 \%)$ and item 6 with $24(30.4 \%)$ respondents.

6. Item 5 had $20(25.3 \%)$ at 5 (more than once daily) followed by item 1 and item 3 with 13 (16.5\%) respondents each.

Table6. Frequencies, means and standard deviations for internet use scales items

\begin{tabular}{|l|l|l|l|l|l|l|l|l|}
\hline & \multicolumn{9}{|c|}{ Score } & $M$ & $S D$ \\
\hline Item & 0 & 1 & 2 & 3 & 4 & 5 & & \\
\hline 1 & $6(7.6)$ & $23(29.1)$ & $1(1.3)$ & $32(40.5)$ & $4(5.1)$ & $13(16.5)$ & 2.56 & 1.55 \\
\hline 2 & $15(19.0)$ & $30(38.0)$ & $10(12.7)$ & $16(20.3)$ & $4(5.1)$ & $4(5.1)$ & 1.70 & 1.39 \\
\hline 3 & $12(15.2)$ & $19(24.1)$ & $17(21.5)$ & $11(13.9)$ & $7(8.9)$ & $13(16.5)$ & 2.27 & 1.67 \\
\hline 4 & $19(24.1)$ & $31(39.2)$ & $14(17.7)$ & $7(8.9)$ & $3(3.8)$ & $5(6.3)$ & 1.48 & 1.39 \\
\hline 5 & $13(16.5)$ & $16(20.3)$ & $9(11.4)$ & $12(15.2)$ & $9(11.4)$ & $20(25.3)$ & 2.61 & 1.85 \\
\hline 6 & $24(30.4)$ & $20(25.3)$ & $10(12.7)$ & $12(15.2)$ & $6(7.6)$ & $7(8.9)$ & 1.71 & 1.63 \\
\hline 7 & $25(31.6)$ & $20(25.3)$ & $6(7.6)$ & $9(11.4)$ & $10(12.7)$ & $9(11.4)$ & 1.82 & 1.78 \\
\hline 8 & $30(38.0)$ & $23(29.1)$ & $9(11.4)$ & $10(12.7)$ & $2(2.5)$ & $5(6.3)$ & 1.32 & 1.47 \\
\hline 9 & $14(17.7)$ & $29(36.7)$ & $18(22.8)$ & $7(8.9)$ & $4(5.1)$ & $7(8.9)$ & 1.73 & 1.46 \\
\hline
\end{tabular}

Note: Percentages in brackets

Table 6 further indicates that the Internet was mostly used for: For fun/leisure (e.g., playing online games, facebook, tweeter, etc) (Item 5), Search for information for my academic tasks (e.g., assignments, projects, essays, etc) (Item 1) and E-mail friends for non-academic purposes (e.g., socialization, national news, domestic affairs, etc) (Item 3). This observation agrees basically with Onwuagboke et al.'s findings that ranked the top four major purposes of Internet as (a) social networking, (b) searching for school related materials, (c) communication and (d) general information searching. Adediran and Kehinde (2014) and Lei (2009) place social networking as the most important use. On average, pre-service teachers in this sample used internet "at least several times in a month" compared to Firat and Serpil's (2017) sample of an average 1.65 hours per day.

Further analysis was conducted by categorizing the total score of internet use - the sum of the scores from each item (score, $\mathrm{X}$ ) for each respondent and labeled as follows:

- $\quad$ Non-users $=$ "Never $=0 "$

- $\quad$ Low-users $=$ "several times in semester $=1 "$ and several times in a month $=2 "$

- $\quad$ Moderate users $=$ "several times a week $=3 . "$

- High users $=$ "once daily $=4$ " and "more than once daily $=5$ ". 
Table 7 shows that majority of the respondents 54(68.47) were low internet users, only 6(7.6\%) were high users of internet and 6(7.6\%) are non-users at "never." These observations indicate that internet use by undergraduate elementary school teachers is still low.

Table7. Respondents' Internet user categories

\begin{tabular}{|c|c|c|}
\hline Internet Use & Score $(X)$ Range & Frequency \\
\hline Non-Users & $0 \leq X<4.5$ & $6(7.6)$ \\
\hline Low users & $4.5 \leq X<22.5$ & $54(68.4)$ \\
\hline Moderate users & $22.5 \leq X<31.5$ & $13(16.5)$ \\
\hline High users & $31.5 \leq X \leq 45$ & $6(7.6)$ \\
\hline
\end{tabular}

\section{Research question 3}

What demographic factors affect pre-service teachers' internet use?

To answer this question, the sources of internet; phone, library, cyber cafés, and modem were added to the previous demographic variables: gender, computer ownership, age and year of study. Inferential data analyses were carried out in two ways (Table 8):

1. Computation of (a) independent samples $t$ tests for gender, computer and sources of internet ownership and (b) ANOVA for age and year of study by internet use scale score.

2. Computation of $\chi^{2}$ statistics for all the demographic valuables with internet users' categories (nonusers, low users, moderate users and high users).

Examination of Table 8 reveals that all demographic variables were not statistically significant determinants for internet use by pre-service teachers. Notably being male or female does not determine internet usage in agreement with other findings (Firat \& Serpil (2017); Helsper, 2010; Ogunlade, Fagbola, Ogunlade \& Amosa, 2015; and Onwuagboke et al., 2014). This finding is contrary to that of Adediran and Kehinde (2014) who found significant difference between male and female participants with male higher usage than their female counterparts.

Pre-service teachers' ages did not discriminate the extent of internet usage among them. This finding is congruent to Onwuagboke et al. (2014) who found no statistically significant difference in the frequency of internet usage among age groups (16-19, 20-24 and greater than 25 years).

The year of study did not significantly affect extent of internet usage contrary to Firat and Serpil (2017) finding who established significant differences with respect to year (class) of study - internet usage increased with year of study. Neither the type of source of internet services discriminated between pre-service teachers' extent of internet usage or owning a computer (or not) did not determine internet usage.

For individual items, computation of $t$-statistics (for gender, computer ownership) and $F$-statistics (for age and year of study) revealed that two items (5 and 8) were statistically significant differences in the means between computer owners and non-owners [item 5: $(77)=2.123, p=.037$, Items 8: $t(77)=$ 2.678, $p=.009]$.

Table8. $F / t$ and $\chi^{2}$ statistics for independent variables by internet use

\begin{tabular}{|l|l|l|l|l|l|}
\hline \multicolumn{2}{|l|}{ Internet Use (Means) } & $t / F$-ratio & $P$ & \multicolumn{3}{l|}{ Internet Use (User-categories) } \\
\hline & $t(77)=-0.93$ & .357 & 4.05 & $p$ & $d f$ \\
\hline Gender & $t(77)=1.52$ & .132 & 2.45 & .256 & 3 \\
\hline Computer Ownership & $F(4,74)=0.96$ & .415 & 8.49 & .480 & 3 \\
\hline Age & $F(4,74)=1.48$ & .228 & 9.90 & .359 & 9 \\
\hline Year of Study & & & & & 9 \\
\hline Source of Internet & $t(77)=0.16$ & .876 & 0.34 & .952 & 3 \\
\hline Phone & $t(77)=-0.95$ & .346 & 2.01 & .570 & 3 \\
\hline Library & $t(77)=-1.41$ & .163 & 1.42 & .702 & 3 \\
\hline Cyber Cafes & $t(77)=-0.10$ & .927 & 1.86 & .601 & 3 \\
\hline Modem & & & & & \\
\hline
\end{tabular}

\section{DisCUSSION}

\section{Elementary Pre-Service Teachers' Source of Internet}

The phone is becoming a favourite source of internet for pre-service teachers. This observation indicates an increasing tendency to use personalized internet services (i.e., portable and cheap). This 
finding can be explained in two ways. First, mobile phone service providers in Kenya (e.g. Safaricom, Orange and Airtel) are offering competitive internet services. For instance, weekly internet data bundles (e.g., Ksh 5 for 5 MB or Ksh 50 for 65 MB Safaricom, [Kenya Shilling, KSh $105=1$ US dollar]) and daily or monthly subscriptions. However, capabilities of most phones owned by students allow customized and limited htm or html web pages, (not 'Word' and/or portable document format, pdf) which most academic information is presented such as journal articles. The emergence of enhanced and affordable smart phones will eventually mitigate this weakness. The second explanation is the affordability of internet-enabled phones at a cost of as low as KSh 1000 and Tablets going for less than KSh 10 000. On the other hand, low use of free internet from the college library is a function of the available of computers, phones and Tablets that are WI-FI enabled. The WI-FI hotspot strength fluctuates and thus not reliable. A general opinion from the respondent pointed to this fact.

The accessibility of the internet was originally provided by commercial service providers such as cyber cafes and their use is decreasing. Although cyber cafes have had their prices fluctuating and dropping as low as KSh 60 per hour, their use is declining. The decreasing popularity of cyber cafes can be attributed to:

1. Lack of flexibility. The internet service, other than the "student centre" and few students offering this service in their hostel rooms, most cyber cafes are not adaptable to students access and use due to site or location, time of usage and the large number of "other" users;

2. Cumulative cost. The overall cost of internet service is expensive because productive use of internet services requires extended and frequent periods of use.

Use of a modem is a new phenomenon expected to promote internet use, however, (a) use of a modem dictate easily accessible computer (PC or Laptop) to the student. Low computer ownership will directly lead to low modem usage and (b) modem speeds (slightly above $200 \mathrm{kbps}$ ) persistently fluctuating particularly with commercial offers by service providers. The broad band connectivity through fiber optic is not yet an internet reality to the majority in spite of the advocacy of $4 \mathrm{G}$ connectivity.

\section{Capacity of internet usage by elementary pre-service teachers}

Clearly from the findings of this study, the internet is not yet a "domesticated" technology by preservice teachers. This is despite of the free availability of internet in college libraries and internetenabled phones whose cost is decreasing. Nonetheless, internet usage should be considered under:

1. If students' academic or non-academic tasks do not demand use of internet then usage is minimally.

2. The academic tasks such as assignments, take-away homework, continuous assessment tests and course announcements still follow traditional mode. These traditional modes are use of books, handouts and journals in the library and notice boards or class representatives for announcements.

\section{Effects of independent variables on elementary pre-service teachers' internet use}

Gender is not a determinant of internet usage. This finding indicates that encouraging use of the internet will bridge the mystified gender differences or gap that exists in computer/internet use. Though, caution should be taken into consideration not to overemphasize this finding since there could be unexplained mediating variables.

Bahk (2008) indicated that computer ownership had positive relationship with undergraduates' internet involvement (usage). However, in this study computer ownership was not a sufficient condition for internet usage due to the following two reasons: (a) owning a computer does not necessarily imply owning the internet facility and (b) there are other compensatory sources of internet other than the computer (e.g., phones, Tablets).

Age does not affect internet use contrary to the findings of Bahk (2008) who contended that age is a predicator of internet usage (involvement). A possible explanation for this finding is the narrow age range of respondents in the study (19-30 years). Therefore, age-range was not wide enough to indicate variations in internet usage.

The year of study did not determine internet usage by pre-service teachers. This observation has two possible explanations: 
1. Students' tasks across the years of study are similar in the requirements for use or non-use of internet.

2. Year of study has a strong positive correlation with age of the respondents. Consequently, the two variables behave similarly.

Finally internet sources (phone, library, cyber cafes and modem) do not affect internet use since their usages appear compensatory. That is, if one source is not available for use; one or more of the other sources are available.

\section{Conclusions}

The study investigated: Source of internet use, Capacity of internet use and Demographic variables as possible determinant of internet usage by pre-service Early Childhood and Primary Education teachers. From the results of the study, it is concluded that for pre-service ECPE teachers. (a) The mobile phone is increasingly becoming a major source of internet services at the expense of computers in college libraries, (b) The use of internet is still quite low and (c) The demographic variables under study are not determinants for pre-service ECPE teachers internet usage.

\section{RECOMMENDATIONS}

From the results of this study, the following three recommendations are made:

1. As computer ownership by university students is encouraged and facilitated (for example Microsoft and Safaricom laptop offers) this laptops or tablets should be Wi-Fi enabled to boost students getting internet directly from the college library. This source however is expected to increase as a result of dropping prices.

2. Internet - connected computers in the library should still be provided, and the number should be increased to correspond to the surge in number of university students. It should be noted here that laptop acquisition may not be a priority to most students who may not be financially secure. Thus, internet from the library will remain their choice.

3. University lecturers should be encouraged to make use of the emerging technologies (internet) for academic tasks to students. It is only then that students will take responsibility to make use of the internet.

\section{REFERENCES}

Adediran, E.M.T., \& Kehinde, A.O. (2014). Gender and internet use pattern of pre-service teachers in Nigerian College of Education. International Letters of Social and Humanistic Sciences, 19, 6675. doi: 10.18052/www.scipress.com/ilshs.19.66

Aladojana, F. (2007). The implications of ICT and NKS for science teaching: Whither Nigeria. Complex Systems, 17, 113-124

Bahk, C.M (2008). Reliance, Immersion and enjoyment; an exploratory socio analysis on internet. Communication of IIMA, 8(1), 59-66

Firat, M.., \& Serpil, H. (2017). Comparing the Internet usage of pre-service Language teachers with teachers of other subjects: Distance learning vs. On-campus learning. Profile, 19(1), 55-72. Doi:10.15446/profile.v19n1.54184

Keller, C., Lindh, J., Harastinki, S., Casanovas, I., \& Fernandez, G. (2009). The impact of national culture on e-learning implementations a comparative study of an Argentinean and a Swedish University. Education media international, 46 (1), 67-80

Lei, J. (2009). Digital natives as pre-service teachers: What technology preparation is needed? Journal of Computing in Teacher Education, 25,(3), 87-97

Mishra, M.K. (2009). Use and importance of the Internet at the University of Maiduguri, Nigeria. First Monday: Peer Reviewed Journal on the Internet, 14(3). Retrieved from http://firstmonday.org/htbin/cgwrap/bin/ojr/index.php/fm/article/viewArticle/2301/2118

Ogunlade, O.O., Fagbola, O.F., Ogunlade, A.A., \& Amosa, A.A. (2015). Assessment of utilization of internet facilities among pre-service teachers in University of Ilorin, Nigeria. Malaysian Online Journal of Education Technology, 3(3). 
Onwuagboke, B.B.C., Singh, T.K.R., Fook, S.F. (2014). Pre-service teachers' internet usage a function of demographic factors: The case of a Nigerian College of Education. Journal of Education and Learning, 8(4), 299-308

Omotayo, B.O. (2006). A survey of internet access and usage among undergraduates in an African University. The International Information and Library Review, 38, 215-224

Smith, J.J., Greene, C.H. (2013). Pre-service teachers use E-learning technologies to enhance their learning. Journal of Information Technology Education: Research, 12, 121-140

Helsper, E.J. (2010). Gendered internet use across generations and life stages. Communication Research, 37(3), 352-374

Society for Information Technology and Teacher Education (2002). Basic Principles (online). Available LAP: //www.aace.org/site

UNESCO (2002). Information and Communication Technologies in teacher education: a planning guide. UNESCO

Yidrim, F., Korucu, O., Aktas, C., \& Kule, G. (2010). E-learning education system in universities with instructors' perceptions: A survey in Turkey. International Journal of Social Sciences and Humanity Studies, 2(1), 25-31.

\section{AUTHORS' BIOGRAPHY}

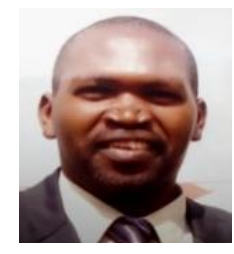

Philip K. Mwei, has a PhD in Educational Communication and Technology. He is currently a lecturer of Mathematics Education and Educational Technology at Moi University. He has authored a book, co-authored a book chapter, written and published papers in refereed journals and presented in International conferences.

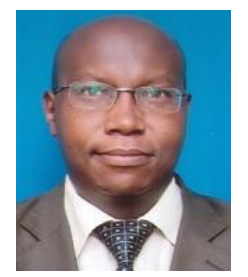

Jackson K. Too, is a Professor of Educational Media \& Technology of Moi University. Has co-authored a book, written and published papers in refereed journals. Was involved in developing a Teacher Education Diploma Program for Refugees in Dadaab. Currently, Senior Assistant Commission Secretary, Research \& Development in the Commission for University Education. 